\title{
Turismo y desarrollo: visiones de los candidatos a intendente en Mar del Plata. Elecciones de 1973 y 1983
}

\author{
Tourism and Development: Visions of the Candidates to \\ Intendent in Mar del Plata. 1973 and 1983 Elections
}

\author{
Daniela Castellucci \\ Universidad Nacional de Mar del Plata
}

DOI: $\underline{\text { https://doi.org/10.25032/crh.v6i10.9 }}$

Recibido: 31/3/2020

Aprobado: 12/6/2020

Resumen En Argentina, durante el período 1966-1983, el gobierno estuvo mayoritariamente en manos del poder militar, donde transcurrieron dos procesos electorales previos al retorno de la democracia, en 1973 y 1983, respectivamente. Si bien fueron años en donde primó la gestión pública en manos de los militares, los actores políticos civiles también participaron de la arena política. En este sentido, el presente artículo se centra en el elenco político local en estas dos contiendas electorales buscando analizar y comparar las visiones de los candidatos a Intendente respecto del turismo y el desarrollo de la ciudad en el momento de presentar sus propuestas políticas, a fin de identificar sus creencias y valoraciones en torno al desarrollo turístico. Desde una perspectiva de la historia social del turismo se pretende contribuir a la comprensión de las características que asumió la mencionada problemática local en esos años.

Palabras clave: Turismo - Desarrollo - Elecciones - Política

\begin{abstract}
In Argentina, during the period 1966-1983, the government was largely in the hands of the military power, while two electoral processes took place before the return of democracy, in 1973 and 1983 respectively. Although these were years in which public management in the hands of the military prevailed, civilian political actors also participated in the political arena. In this sense, this article focuses on the local political
\end{abstract}


cast in these two electoral disputes seeking to analyze and compare the views of the mayoral candidates regarding tourism and the development of the city at the time of presenting their political proposals, in order to identify their beliefs and valuations regarding tourism development. From a perspective of the social history of tourism, the aim is to contribute to the understanding of the characteristics that local tourism development assumed in those years.

Keywords: Tourism - Development - Elections - Politics

\section{Introducción}

Mar del Plata, ciudad cabecera del Partido de General Pueyrredon (Buenos Aires, Argentina), tuvo su origen turístico vinculado a la actividad balnearia a fines del siglo XIX, transformándose luego en uno de los principales destinos de turismo nacional del país (Pastoriza 2011). De centro receptor del ocio de elite finisecular pasó a ser el balneario de las clases medias y trabajadoras hacia mediados del siglo Xx. En la década del sesenta la ciudad logra consolidarse como destino turístico masivo de Argentina producto de iniciativas privadas y políticas públicas impulsadas por los conservadores en los años treinta para «democratizar» el balneario y continuadas posteriormente por el peronismo en los años cuarenta y cincuenta (Pastoriza y Torre 2019).

Durante la primera mitad del siglo $\mathrm{xx}$ su estructura productiva se fue consolidando sobre la base de los servicios de entretenimiento acompañados de la construcción y la pesca, que también contribuyeron a su incipiente desarrollo económico y social. La realidad local fue modificándose y si bien las actividades turísticas, de la construcción y de la pesca eran consideradas por la sociedad tradicional marplatense las principales de la ciudad, al promediar los años sesenta esta situación cambió. Ciertos actores económicos al percibir las debilidades de la centralidad otorgada al turismo, comienzan a plantear alternativas para el desarrollo local proponiendo la diversificación productiva a través del fortalecimiento del sector industrial en sus diversas ramas (alimentación, textil, calzado, madera y muebles, plástico, papel, química, minerales no metálicos y metalmecánica). Este debate entre 
turismo e industria como bases de la economía local se va a mantener a lo largo del tiempo hasta la actualidad.

El golpe de Estado de 1966, autodenominado Revolución Argentina, conllevó la puesta en marcha de nuevas políticas económicas marcando un cambio en la gestión pública del turismo a nivel nacional que tuvo sus implicancias en el ámbito local. Tras un breve interregno de gobierno democrático peronista (1973-1976) a nivel nacional y socialista a nivel local, los militares volvieron a tomar el poder en el país bajo el llamado Proceso de Reorganización Nacional hasta 1983, año en que retorna nuevamente la democracia. Durante este período (1966-1983) el Gobierno estuvo mayoritariamente en manos del poder militar, en los cuales a la vez que transcurrieron dos procesos electorales previos al retorno de la democracia, en 1973 y 1983 respectivamente.

Si bien fueron años en donde primó la gestión pública en manos de los militares, los actores políticos civiles hallaron formas de participación de la arena política en los momentos señalados. En este sentido, el presente artículo se centra en el elenco político local en las dos contiendas electorales buscando analizar y comparar las visiones de los candidatos a intendente respecto del turismo y el desarrollo económico de la ciudad en el momento de presentar sus propuestas políticas. Desde una perspectiva de la historia social del turismo y de la política se pretende contribuir a la comprensión de las características de este proceso de desarrollo de Mar del Plata en esos conflictivos años; a la vez que generar conocimiento sobre experiencias de destinos turísticos latinoamericanos, en particular en escenarios locales, durante la segunda mitad del siglo xx.

En la perspectiva de analizar las visiones de los actores políticos locales en torno a las mencionadas problemáticas se ha explorado un corpus conformado por fuentes periodísticas de la prensa local (El Atlántico y La Capital). En este sentido se han analizado las notas periodísticas y las entrevistas realizadas a los candidatos a intendente, publicadas en estos medios durante los meses de enero, febrero y marzo de 1973 y octubre de 1983. Esta estrategia metodológica permite identificar los aspectos centrales que la mayoría de los candidatos a intendente consideraban dar a conocer al electorado marplatense a fin de conseguir su voto. De modo tal que en dichas propuestas electorales se ha buscado advertir la visión de estos actores políticos respecto de las categorías analíticas mencionadas, intentando identificar a la vez el 
modo en el que quedaban plasmados los intereses de determinados actores socioeconómicos predominantes ${ }^{1}$ del campo local. Asimismo, desde un enfoque subjetivo, interesa analizar las perspectivas (valores y creencias) de los candidatos a partir de sus propios testimonios. Se ha partido de la consideración que a partir de la lectura de las notas periodísticas de la prensa marplatense al elenco local es posible encontrar alteridades, posicionamientos discursivos e ideológicos (Gil 2010). Queda claro que el hecho de tomar como fuente los ejemplares de los dos diarios locales permite tener un panorama más inteligible (no necesariamente suficiente) de cuáles eran las visiones respecto del turismo y el progreso económico en la ciudad. Sin perjuicio de considerar que para reconstruir estas visiones de un modo más acabado sería necesario complementarlas con la aplicación de otros recursos metodológicos, se estima que el uso de los archivos de los diarios resulta pertinente para una primera aproximación al tema objeto de estudio.

De esta forma, en el presente trabajo se da cuenta de un estudio vinculado con el pasado reciente de la Argentina, específicamente con el proceso de retorno a la democracia en dos momentos de la historia nacional, en 1973 y 1983, en la ciudad de Mar del Plata. Esta historia del pasado reciente hace referencia a hechos sociales y políticos de un tiempo cercano al presente pero que no se encuentra vinculado a situaciones dramáticas y procesos traumáticos como sí lo ha venido haciendo la amplia producción de la historia reciente en Latinoamérica. ${ }^{2}$ En este sentido, al analizar y comparar dos momentos nos da cuenta de la variación en las visiones de los actores políticos locales, permitiendo comprender como a partir de sus valores y creencias, estos pudieron ser determinantes en la construcción de políticas públicas durante sus posteriores gobiernos con el objetivo de lograr un desarrollo económico integral más

\footnotetext{
${ }^{1}$ Ricardo Sidicaro entiende por actores socioeconómicos predominantes al heterogéneo conjunto de agentes cuyas actividades gravitan de manera estratégica sobre una determinada economía y cuyas acciones u omisiones tienen implicancias en el conjunto de las relaciones sociales. Pueden ser un gran número de empresas que producen determinados bienes o brindan los mismos servicios, firmas que ocupan posiciones monopólicas, o grandes inversores ocasionales. Se considera su situación de predominio a partir de su capacidad para gravitar sobre la orientación de determinada economía y condicionar u orientar la toma de decisiones estatales. Al respecto ver Ricardo Sidicaro, Los tres peronismos: estado y poder económico, Buenos Aires, Siglo Veintiuno Editores, 2017.

${ }^{2}$ En este sentido, Marina Franco y Florencia Levín señalan que si bien no hay razones epistemológicas o metodológicas para que la historia reciente quede circunscripta a temas traumáticos (guerras, masacres, genocidios, dictaduras, crisis sociales); lo cierto es que en los países latinoamericanos que han atravesado regímenes represivos, ha sido el carácter traumático de ese pasado lo que generalmente ha intervenido en la delimitación del campo de estudios. Al respecto, Marina Franco y Florencia Levín, Historia reciente. Perspectivas y desafios para un campo en construcción, Buenos Aires, Paidós, 2007.
} 
equilibrado y revertir el proceso de agotamiento del turismo masivo, durante los años setenta y ochenta.

\section{Las elecciones de 1973: el camino hacia una democracia efímera}

A inicios de la década del setenta, en Argentina se comienza a esbozar una nueva salida electoral ante el deterioro del proyecto de la Revolución Argentina, que fuera iniciado en junio de 1966. Relevado el general Onganía del cargo de presidente por el general Levingston en junio de 1970, el nuevo gobierno se vio obligado finalmente a recurrir a una salida política a través del llamado a elecciones. Ante el nuevo contexto que se abría, un grupo de partidos políticos, liderados por los peronistas 3 y radicales, 4 dieron a conocer el documento La Hora del Pueblo en noviembre de 1970. En este escrito se reclamaba al gobierno militar una salida electoral sin vetos ni proscripciones, la defensa del mercado interno y el capital nacional, y el aumento de los salarios (Persello 2015).

En esos años el clima político estaba dominado por una violencia muy particular, tanto en sus modalidades como en su intensidad. El contexto socioeconómico también se hallaba sumamente deteriorado. La elevada inflación, la fuga de divisas, la caída del salario real y el desempleo habían contribuido a su deterioro y la ola generalizada de reclamos lo había agravado, por lo que la cuestión del desarrollo seguía quedando postergada. El tema de la seguridad también era acuciante y era algo que el gobierno militar ya no podía garantizar. No había un consenso en el gobierno mismo sobre cómo enfrentar a las organizaciones armadas y la protesta social. Así, en marzo de 1971, el presidente Lanusse anuncia el restablecimiento de la

\footnotetext{
3 En Argentina, durante la segunda mitad del siglo xx, el peronismo desempeñó un papel muy importante en las relaciones políticas nacionales. El Partido Justicialista fue fundado por Juan Domingo Perón en 1946 y durante sus primeros gobiernos se impulsaron diversas transformaciones de la sociedad y del Estado. En su experiencia fundacional se consolida el proyecto de un Estado intervencionista y de una mayor equidad social. Sin embargo, entre 1955 y 1972 el peronismo se convirtió en un movimiento político de organización e ideología imprecisa debido a la proscripción de su líder, tras el golpe de Estado de 1955, generándose diversas facciones dentro del partido. A pesar de estos conflictos, los sectores populares continuaron fieles a su líder político. Al respecto ver Ricardo Sidicaro, Los tres peronismos: estado y poder económico, Buenos Aires, Siglo Veintiuno Editores, 2017.

4 En este sentido, Andrés Malamud sostiene que desde mediados del siglo xx el sistema partidario argentino estuvo caracterizado por una dinámica bipartidista entre el PJ y la Unión Cívica Radical (UCR), principalmente en el orden presidencial. La UCR es el más longevo de los actuales partidos argentinos, data de 1891, y desde sus inicios se ha constituido en representante de los excluidos sectores medios. Al respecto ver Andrés Malamud, «El bipartidismo argentino: evidencias y razones de una persistencia (1983-2003)», Revista Uruguaya de Ciencia Política, Vol. 4, N. 1, 2004, pp. 137-171.
} 
actividad política partidaria, poniendo fin a la proscripción de los partidos políticos, y convoca a elecciones generales, que finalmente se efectuarían el 11 de marzo de 1973. Entendiendo que la «Hora del Pueblo» era un punto de partida, el gobierno puso en marcha dos estrategias complementarias convocando a un Gran Acuerdo Nacional (GAN), por un lado, y proyectando una enmienda a la Constitución que establecía modificaciones al régimen electoral, por el otro (Romero 2015). En abril de 1972 se quitaron las restricciones a la actividad de los partidos políticos y estos comenzaron los procesos de reorganización interna e iniciaron sus campañas frente a la nueva contienda electoral.

De acuerdo a lo dispuesto por las leyes nacionales 19895 y 19905, a principios de enero de 1973 se convocó al electorado a elecciones para el domingo 11 de marzo. A nivel nacional el Frente Justicialista de Liberación (Frejuli),5 junto a la UCR, encabezaron la contienda, aunque sus resultados hicieron innecesario el ballotage. Sin embargo, la realidad política de Mar del Plata distaba del escenario nacional. En esta ciudad, el socialismo tenía una importante trayectoria en su vida política lo que determinaría el resultado de las elecciones a intendente. ${ }^{6}$ En este proceso, es el Partido Socialista Democrático (PSD), 7 quien encabezó la disputa junto al Frejuli, el acceso a la intendencia.

\section{Las elecciones en Mar del Plata}

En el Partido de General Pueyrredon se postularon nueve candidatos a intendente. Los partidos políticos paulatinamente se fueron organizando internamente. Se convocó a reuniones para trabajar sobre las plataformas y precisar

\footnotetext{
5 El Frente Justicialista de Liberación fue una alianza electoral frente al llamado a elecciones presidenciales de marzo de 1973, integrada por el Partido Justicialista, el Movimiento de Integración y Desarrollo, el Partido Intransigente, el Partido Conservador Popular y el Partido Demócrata Cristiano. Persello, «Las elecciones....», 235-363.

${ }^{6}$ Elisa Pastoriza, «Sociabilidad política en Mar del Plata. Manifestaciones, discursos y enfrentamientos en torno a las elecciones del 24 de febrero de 1946». Prácticas de sociabilidad en un escenario argentino. Mar del Plata 1870-1970. Graciela Zuppa. (Mar del Plata: Universidad Nacional de Mar del Plata, 2004), 81-105.

7 El Partido Socialista fue fundado en Argentina el 28 de junio de 1896 y a partir de 1955 pasa a denominarse Partido Socialista Democrático. En particular, la ciudad de Mar del Plata cuenta con una arraigada tradición socialista en su historia política que la diferencia del resto del país. Pese a su condición de villa balnearia de la élite porteña a principios del siglo XX, el municipio se convirtió en uno de los pocos donde los socialistas accedieron al poder en los años veinte, y en los años treinta y cuarenta se mantuvieron en el deliberativo. A partir de las elecciones de 1958, sus candidatos a intendente volvieron al poder en las tres siguientes contiendas electorales hasta su última victoria en marzo de 1973. $\mathrm{Al}$ respecto ver Elisa Pastoriza y Guillermo Cicalese, «Una trayectoria poco común...» 24-33.
} 
tareas y aspectos relativos a las campañas electorales ${ }^{8}$. Además, fueron abriendo centros de información en distintos puntos de la ciudad para que el electorado marplatense pudiese consultar los padrones, inscribirse como fiscales de mesa, como así también informarse de las propuestas de gobierno, a la vez que exponer sus problemáticas barriales. Los partidos políticos empezaron a trabajar más formalmente en las campañas electorales a mediados de enero de 1973, pero es recién en el mes de febrero y principios de marzo que la actividad proselitista comenzaría a desarrollarse con mayor intensidad. Durante la campaña en el país, el gobierno militar fue fijando reglas ad hoc para intentar encuadrarla. No obstante, el clima político lo frenaba y el proceso electoral no quedó exento de prácticas intimidatorias y coercitivas. En Mar del Plata, a diferencia de otros partidos políticos, el Frejuli inició su campaña a fines de enero de 1973 y luego de sufrir atentados contra militantes y simpatizantes peronistas, a mediados de febrero, decidió no realizar más actos públicos. Hubo partidos que fueron objeto de atentados en sus locales o sus militantes fueron intimidados en la vía pública.

A pesar de estos hechos, la campaña electoral continuó desarrollándose cada vez con mayor intensidad. Dado que las elecciones transcurrieron durante la temporada estival, la ciudad fue centro no solo de las corrientes turísticas sino también de importantes figuras del elenco político nacional. Los candidatos presidenciales junto a los locales presentaban sus plataformas partidarias, aunque en algunos casos se advertía cierta languidez cuando se desarrollaban las propuestas en el plano local. En la difusión de sus plataformas, los candidatos a intendente hicieron uso de los espacios en radio y televisión de orden local, emplearon la publicidad gráfica en los diarios locales, y realizaron actos públicos en las sedes y centros informativos de cada partido, y en diversos espacios públicos. En particular, la televisión como medio de difusión de la propaganda política, ocupo un lugar preponderante en relación con los otros instrumentos de difusión, dado que con menor esfuerzo se llegaba a difundir las plataformas electorales a audiencias masivas. Además de estas acciones los candidatos

\footnotetext{
${ }^{8}$ Según Norma Álvarez, se entiende por campaña electoral al conjunto de actividades que llevan a cabo los partidos políticos para promover sus candidaturas y obtener el voto de los ciudadanos. Es decir, la campaña electoral implicaba tanto la propaganda como el contacto directo con los ciudadanos, era el momento en que los candidatos se acercaban al electorado para ser re-conocidos. Al respecto, Norma Álvarez, «Campañas electorales y estilos políticos: el Partido Justicialista y la Unión Cívica Radical en un municipio de Misiones, 1999", en Samel Amaral y Susan Stokes, Democracia local. Clientelismo, capital social e innovación política en la Argentina. Samuel Amaral y Susan Stokes, Caseros, Eduntref, 2005, pp. 36-56.
} 
a intendente dieron charlas en entidades profesionales y mantuvieron reuniones con agentes económicos y actores sociales de la comunidad local a fin de tomar conocimiento de sus problemáticas e inquietudes.

Ahora bien, ¿cuáles eras esas problemáticas que presentaba la ciudad? Una de las principales preocupaciones de los actores socioeconómicos predominantes 9 era el referido a la crisis económica del balneario. Al promediar los años sesenta algunos actores económicos comenzaron a plantear la necesaria diversificación productiva local a través del fortalecimiento del desarrollo industrial en sus diversas ramas. En efecto, los empresarios entendían que la economía de la ciudad se hallaba frente a un cuadro de crisis progresiva, con un estancamiento de la actividad económica general que el sector turístico no podía revertir. De hecho, una de las principales inquietudes de la Unión del Comercio, la Industria y la Producción (UCIP), en la década del sesenta, era el bajo nivel de productividad de la economía local dado que estaba centrada casi exclusivamente en los servicios turísticos y en la construcción, actividades de carácter estacional y de inestabilidad cíclica. Desde el aspecto social, esta problemática económica se traducía, entonces, en el carácter temporario del empleo en estos dos sectores. Además, la deficiencia estructural de la economía local se agudizaba por la débil participación del producto industrial que se generaba en forma ineficiente en pequeños y numerosos establecimientos sin escala de producción adecuada, como la del calzado y la textil (Álvarez y Reynoso).

La UCIP inició el debate turismo versus industria en la ciudad a principios de la década del sesenta, despertando molestias en aquella parte de la sociedad tradicional marplatense (Bolsa de Comercio de Mar del Plata, Centro de Constructores y Anexos de Mar del Plata, Asociación de Hoteles, Restaurantes, Confiterías, Bares y Afines) que defendía a ultranza la economía turística. El turismo ya no debía ser una actividad central en la economía local, era imperioso plantear para la ciudad la variante industrialista. Es por ello que la UCIP, en la convicción de la necesidad de tomar medidas, propuso poner en marcha un plan de industrialización para suplir o complementar los ingresos producidos por el turismo a partir de la construcción del Parque Industrial de Mar del Plata, que recién pudo concretarse a fines de la década

9 Entre estos actores se encontraban: Unión del Comercio, la Industria y la Producción de Mar del Plata; Bolsa de Comercio de Mar del Plata; Centro de Constructores y Anexos de Mar del Plata; Asociación de Hoteles, Restaurantes, Confiterías, Bares y Afines; Rotary Club; Club de Leones de Mar del Plata. 
del setenta. Se introducía, así, un debate que en los años setenta y principios de los ochenta adquiriría mayor relevancia, la discusión entre la ciudad turística y la ciudad industrial (Castellucci 2014).

Además, en la localidad se presentaban distintos problemas de índole urbano. A principios de la década del setenta los empresarios y profesionales de la construcción se encontraban preocupados por la falta de actualización del Plan Regulador. Asimismo, se denunciaban como problemáticas que retardaban el desarrollo regional: la ineficiente operatividad del puerto; la antigua estructura ferroviaria y su incorrecta localización; el inadecuado manejo del crédito del gobierno militar y los escasos estímulos al fomento de la inversión en la región. ${ }^{10}$ Por otra parte, en la prensa local los actores sociales denunciaban varios problemas urbanos que se acrecentaban en la temporada estival, como el desenvolvimiento del tránsito y el creciente deterioro de las calles en la zona céntrica. En los barrios, a estos problemas se sumaban las carencias de los servicios urbanos esenciales. Otra cuestión crítica que iban adquiriendo mayor relevancia en los sectores barriales era la deficiencia habitacional y de servicios públicos (salud y educación) como consecuencia del aumento poblacional en el Partido. ${ }^{11}$

Por último, otra problemática vinculada al turismo era el conflicto por el uso y goce de las playas. En la década del sesenta y principios de los setenta va a continuar el conflicto con el gobierno provincial en torno a la jurisdicción de las playas el cual se había iniciado a principios del siglo Xx. El reclamo por el uso y goce de las riberas formaba parte de la agenda política local como una problemática que había que buscarle una solución. A principio de los años setenta un conflicto entre el Estado provincial y actores privados y su resolución mediante un fallo de la Corte Suprema de Justicia de la Nación incidiría posteriormente en el enfrentamiento entre el gobierno provincial y el municipal. El Estado local interpuso ante el gobierno provincial una serie de acciones legales y administrativas buscando garantizar la prestación de los servicios y resguardar el principal recurso natural sobre el que se basaba su desarrollo turístico a la vez que asegurarse los ingresos de su usufructo.

${ }^{10}$ La Capital [Mar del Plata], ene. 6, 1973, p. 8

${ }^{11}$ De acuerdo a los datos censales la población de Mar del Plata había tenido un importante crecimiento. De 211.365 habitantes en 1960 había pasado a 305.293 en 1970. Al respecto, Municipalidad de General Pueyrredon, Departamento de estadística, «30. ${ }^{0}$ aniversario 1965-1995», Mar del Plata, MGP, 1996. 


\section{Las visiones sobre turismo y desarrollo}

Las propuestas políticas presentadas por los candidatos a intendente giraban principalmente en torno a cuestiones económicas, urbano ambientales y sociales, las cuales adquirían disímil significación y relevancia de acuerdo a la postura ideológica de cada partido político y a los vínculos establecidos con los actores predominantes del entramado socioeconómico local. En la exposición y argumentación de estas proposiciones se trasluce la visión personal que tenían los candidatos a intendente, y en particular respecto del turismo y el desarrollo económico local en la ciudad. Y aquí interesa saber qué lugar ocupaba el turismo en el desarrollo de la ciudad desde sus perspectivas y cómo se piensa el turismo.

El desarrollo económico de la ciudad como problemática en sí, oscilaba entre dos actividades, el turismo y la industria, sobre todo para aquellos candidatos a intendente que entendían que esas eran cuestiones importantes a resolver. En este sentido, para el candidato del PSD, Luis N. Fabrizio, la problemática del desarrollo económico era un asunto que el municipio no podría desentenderse, por lo que el desarrollo de la industria pesquera y la creación del Parque Industrial eran fundamentales. Fabrizio sostenía que Mar del Plata había crecido bajo el impulso de su condición de ciudad turística y «que esta condición no puede ni debe olvidarse. Es más, deben estructurar los instrumentos que otorguen organicidad al desarrollo turístico; pero evidentemente es preciso afirmar su economía con fuentes de trabajo permanente». ${ }^{12} \mathrm{El}$ turismo junto con la construcción habían sido los pilares del desarrollo económico hasta ese momento, pero proporcionaban a la comunidad local fuentes laborales temporales. En esta línea, el candidato socialista afirmaba que se promovería la ubicación de nuevas industrias en el Parque Industrial, provistas de la infraestructura necesaria, y cuya producción tendría que estar destinada a un consumo que superara la frontera del mercado local. Además, la creación de este parque permitiría la generación de nuevas fuentes laborales, otra de las principales preocupaciones de los socialistas. Para Fabrizio la industria de la pesca, de incipiente expansión, también motivaba el interés en su desarrollo por sus posibilidades en el ámbito internacional.

${ }^{12}$ El Atlántico [Mar del Plata], ene. 24, 1973, p. 8 
Asimismo, este candidato se comprometía a gestionar con los gobiernos provincial y nacional la realización de obras de relevancia como la doble mano de la ruta $\mathrm{N}^{\circ}$ 2, la complementación de la ruta 11 y la autopista Mar del Plata-Miramar, por convenio con Vialidad Nacional y Provincial. Estas eran obras públicas que contribuirían al desarrollo económico del Partido y beneficiarían tanto a la industria como al turismo. Para el desarrollo urbano, Fabrizio entendía que era necesaria la actualización del Plan Regulador, dado que debía estar en permanente adaptación y evolución para orientar adecuadamente este desarrollo sin provocar dificultades. Al referirse al turismo sus propuestas eran más modestas. En este punto el candidato socialista planteaba la creación de las secretarías de Recursos y Promoción turística, a fin de atender la nueva circunstancia del traslado del dominio de las playas a la comuna. Por otra parte, impulsaría el desarrollo de las playas hacia el sur del sector céntrico, creando en esa zona una importante infraestructura turística. Así, Fabrizio, con una visión acotada, entendía al turismo como aquella actividad centrada en la temporada estival, basada en su principal recurso natural y por lo tanto su producto turístico, el turismo de sol y playa.

El impulso de la industria también era una preocupación de los candidatos de partidos de izquierda y, en menor medida, la gestión del turismo. En este sentido, el candidato por la Alianza Popular Revolucionaria (APR), José Mercorillo, proponía en su programa fomentar la instalación intensiva de nuevas empresas industriales a través de excepciones impositivas, lo cual permitiría la generación de nuevas fuentes laborales. Respecto de la industria pesquera, postulaba concretar una promoción para ampliar el consumo interno y una acción coordinada con los gobiernos nacional y provincial para la explotación racional de los recursos, apoyar una política exportadora, y crear un mercado municipal de concentración. También planteaba acciones en materia de política agraria, haciendo referencia a la ampliación del cinturón hortícola-ganadero, la habilitación de mercados de concentración municipales, y el impulso a la producción lechera, entre otros aspectos. En cuanto a la actividad turística, Mercorillo se comprometía a «crear la playa municipal en la zona céntrica, revisar las resoluciones que concedieron playas entre el Faro y los Acantilados a la familia Peralta Ramos, [...] y anulación de las concesiones otorgadas para playas de estacionamiento, librándose esos lugares».13 Así, este candidato de izquierda

${ }_{13}$ El Atlántico [Mar del Plata], feb. 27, 1973, p. 8. 
subsume al turismo a la actividad costera centrando su preocupación en las concesiones balnearias y en particular en la revisión de resoluciones sobre determinadas riberas que habían estado en conflicto con determinados actores privados buscando la expropiación de las playas devueltas. Otro aspecto que denota una visión acotada de la cuestión turística local es cuando hace referencia a la necesidad de levantar los ramales ferroviarios, dado que era uno de los medios de transporte público utilizado por los turistas para llegar a la ciudad. En definitiva, para Mercorillo la industria, principalmente la pesquera, se constituía en la base para fortalecer la economía local y asegurar las fuentes laborales y por lo tanto robustecer el desarrollo del Partido.

Del mismo modo Carlos Petroni, candidato a intendente por el Frente de Izquierda Popular (FIP), plantea «hay que romper con el monocultivo de turismo en Mar del Plata, crear el parque industrial y fomentar especialmente la industria de la pesca».14 En línea con la proposición de un gobierno obrero y popular y de «demoler la estructura parásita del régimen oligárquico e imperialista, a dar a las masas la gestión de su propio destino». 15 este candidato hace su interpretación para la actividad turística de la ciudad. Ir contra el monocultivo del turismo era ir contra esa parte de la sociedad tradicional marplatense que intentaba mantener el perfil de esa ciudad turística destinada a las clases medias, de comerciantes y profesionales. También era necesario encontrar en otras actividades productivas las bases para el desarrollo económico local y la industria pesquera parecía cubrir esa expectativa. En las propuestas en turismo, del mismo modo, se advierte su punto de visa sobre la forma de gestionarlo. En este sentido, Petroni sostiene que no deberían otorgarse más concesiones de los balnearios a actores privados dado que esa explotación debería correr por cuenta de la comuna. Por otra parte, dada la centralidad que tiene el trabajador en su visión política del desarrollo turístico, propone implantar un sistema de turismo social similar el modelo peronista y, además, que era necesario que los servicios turísticos fuesen accesibles al obrero.

En otros candidatos a intendente, como Ángel Roig de la UCR o Leonardo Lagos del Partido Socialista de los Trabajadores (PST), también se observa la misma postura

\footnotetext{
${ }_{14}$ El Atlántico [Mar del Plata], mar. 7, 1973, p. 9.
}

${ }^{15}$ La Capital [Mar del Plata], ene. 11, 1973, p. 5. 
de pensar en desarrollar otras actividades productivas por fuera del turismo a fin de superar la crisis económica. En particular, Roig creía que era necesario «romper la antinomia turismo-industria» impulsando sobre todo a esta última. Para ello se requería «el auxilio de los gobiernos centrales para que la obra importante de infraestructura e industrial se lleve a cabo». ${ }^{16}$ En sus propuestas se advierte una preponderancia de acciones destinadas al fomento de la actividad económica en general concibiendo nuevas obras. Así, Roig propone crear el Banco Municipal, establecer un fondo permanente de mejoras y consideraba necesario actualizar el Plan Regulador para dar solución a los problemas de crecimiento urbano y rural. Tanto en sus propuestas como en sus argumentaciones expuestas se advierte que el turismo no era un eje central en su plataforma política. Al hacer referencia a sus proposiciones al respecto plantea crear infraestructura turística en las playas del sur y del norte de la ciudad. Aquí también este candidato piensa las acciones en turismo en función de la gestión de los espacios costeros exclusivamente, centrado en el producto de sol y playa.

$\mathrm{Al}$ observar las cuestiones sociales y urbanas, es posible advertir aquí también cómo se posiciona al residente y sus necesidades, el barrio, frente a las necesidades de los sectores vinculados a las actividades del ocio, la ciudad turística. Mar del Plata en esos años registraba importantes niveles de crecimiento en varios aspectos. Así como la demanda turística aumentaba año tras año, ${ }^{17}$ la población local también se incrementaba aunque a una menor tasa de crecimiento. La situación en los barrios se contraponía a la realidad de las zonas turísticas costeras de la ciudad. En este sentido, las propuestas de los candidatos en el orden social y urbano se inclinaban mayoritariamente a dar respuesta al problema habitacional. El crecimiento en la población local desde la década del cincuenta había originado un déficit habitacional y esto requería la urgente implementación de una política específica a fin de erradicar las villas de emergencias, como así también asegurar el acceso a la vivienda de todos los sectores de la ciudad. Asimismo, los candidatos exponían que era necesario generar políticas respecto a la educación, la salud y la infraestructura urbana (pavimentación,

\footnotetext{
${ }^{16}$ El Atlántico [Mar del Plata], feb. 16, 1973, p. 9.

${ }_{17}$ De 1.450.817 turistas ingresados en la temporada 1960-1961 se pasó a 4.769.349 en la temporada 1972/73. Al respecto, Municipalidad de General Pueyrredon, Departamento de estadística, «30. aniversario 1965-1995», Mar del Plata, MGP, 1996.
} 
alumbrado, desagües, etc.) para atender la demanda de la creciente población residente.

\section{Las elecciones 1983: el camino hacia la democracia definitiva}

El 11 de marzo de 1973 el socialista Luis N. Fabrizio se hizo del poder local y gobernaría la ciudad por tres años hasta el 24 de marzo de 1976 cuando un nuevo golpe de Estado en el país daría por terminado el gobierno democrático. El Proceso de Reorganización Nacional, como así se hizo llamar esta dictadura, duraría siete años. La debilidad del gobierno militar, el fracaso de las políticas implementadas y la consecuente crisis económica e institucional en la que se sumía el país llevó a que en 1983 se iniciara el tránsito hacia la construcción de un régimen político democrático. ${ }^{18}$ La experiencia de la última dictadura, con su autoritarismo extremo, llevó a que muchos sectores de la sociedad argentina revalorizaran el Estado de Derecho y la democracia; y esto fue visible en los medios de comunicación que reflejaron y generaron la opinión pública, como así también en la campaña electoral de $1983 \cdot{ }^{19} \mathrm{Si}$ bien el llamado a elecciones se había realizado el 28 de febrero de 1983 es recién en los tres meses previos al 30 de octubre de 1983 que la actividad proselitista empezaría a desarrollarse con más fuerza, adquiriendo un mayor dinamismo en el mes de octubre. Tanto a nivel nacional como local, la contiende electoral estuvo encabezada por la UCR y el Partido Justicialista (PJ), resultando el primero triunfador en ambos escenarios.

\section{Las elecciones en Mar del Plata}

En el caso particular del Partido de General Pueyrredon se postularon catorce candidatos a intendente. En la campaña electoral local, los candidatos hicieron uso de los medios de prensa, espacios en radio y televisión de orden local, colocaron afiches en la vía pública y realizaron actos públicos en diversos ámbitos. Claro que la dimensión que asumía la campaña electoral de cada partido difería en función de sus posibilidades de financiación. Por otra parte, las estrategias de la propaganda política adoptadas por cada uno de ellos también diferían. En el diario La Capital se señalaba

\footnotetext{
${ }^{18}$ José Luis Romero, Breve historia de la Argentina, Buenos Aires, Fondo de Cultura Económica de Argentina, 2013.

19 María Estela Spinelli, «Rasgos de la cultura política argentina. Un análisis del enfrentamiento peronismo-antiperonismo, 1945-1983», Memorias de la Argentina contemporánea 1946-2002. Marcela Ferrari, Lila Ricci y María Estela Spinelli, Mar del Plata, EUDEM, 2007, pp. 73-99.
} 
que el justicialismo apelaba a la exhibición de viejas imágenes de Juan Domingo Perón en la Plaza de Mayo. Esta modalidad no concordaba con las modernas estrategias publicitarias empleadas por los otros partidos. En contraposición, la UCR había lanzado un filme publicitario por televisión, donde se resaltaba la trayectoria del candidato a intendente y del partido. También realizaron encuentros de candidatos en diversos espacios públicos convocados por diversas instituciones locales, desde centros de estudiantes universitarios hasta entidades financieras. Asimismo, los partidos fueron abriendo centros de información en distintos puntos de la ciudad para que el electorado pudiese consultar las propuestas de gobierno y los que estuviesen interesados se inscribiesen como fiscales de mesa. Además de estas acciones, los candidatos mantuvieron reuniones con diversos agentes económicos (cámaras y asociaciones empresariales y profesionales) y actores sociales de la comunidad local (entidades gremiales, sociedades de fomento, residentes de diversos barrios) con el objetivo de compenetrarse en las problemáticas locales e identificar posibles soluciones. ${ }^{20}$

A inicios de los años ochenta la realidad económica local presentaba un panorama crítico. Al promediar la década del setenta la crisis económica de la ciudad, que había empezado a evidenciarse desde la década anterior dada la centralidad que tenía la actividad turística, comenzó a agudizarse. En 1975 la contracción económica en la ciudad era generalizada. El turismo registraba una caída de ingreso y permanencia de visitantes. También la construcción, la pesca y la industria metalúrgica sufrieron en esos años una notoria retracción de la demanda. Con la implementación del modelo de hegemonía financiera del gobierno militar, tras el golpe de Estado de 1976, esta situación económica se agravó aún más. Para 1981 todos los sectores de la economía marplatense habían entrado en una crisis generalizada (Álvarez y Reynoso).

Respecto de la actividad turística, la imposición del modelo de hegemonía financiera marcó el fin de un tipo de economía basada en gran medida en el turismo masivo. En la década del setenta el turismo en Mar del Plata continuó con su proceso de agotamiento como consecuencia de factores exógenos y endógenos. Por un lado, el aumento del desempleo y la caída del salario real en el país produjeron una retracción

${ }^{20}$ Daniela Castellucci, «Actores políticos y turismo: la visión de los candidatos a intendente sobre el turismo en Mar del Plata en las elecciones de 1983", XV Jornadas Interescuelas/Departamentos de Historia, Universidad Nacional de la Patagonia San Juan Bosco, Comodoro Rivadavia, 2015. 
en el ingreso de turistas de las clases medias bajas. Asimismo, los cambios en los gustos y hábitos de la demanda turística, la consolidación de destinos en el litoral atlántico bonaerense, el dólar depreciado y la competencia de destinos internacionales, incidieron en la reducción de llegadas de los sectores medios y medios altos a la ciudad. Por el otro, la degradación del recurso natural playa, la saturación de los espacios públicos y la aparición de problemas de convivencia entre turistas y residentes contribuyeron también a este agotamiento. Entre 1979 y 1982, la ciudad como medio de producción turística siguió la degradación del aparato productivo nacional intensificándose de esta manera la crisis del turismo masivo (Cicalese 2002).

Así, en términos generales, Mar del Plata no pudo escapar a los impactos sociales del modelo económico de la dictadura y al iniciarse la década del ochenta se hacía sentir una crisis económica que solo fue paliada en parte por las inversiones públicas (nacionales y provinciales) principalmente en la construcción. Durante el período de la última dictadura militar, las administraciones municipales habían realizado una remodelación de la ciudad que buscaba reposicionarla como centro de recreación y turismo del país (Cicalese 2001).

Por otra parte, en la ciudad se manifestaban problemas de carácter urbano y social. En la prensa local se denunciaban diversos problemas urbanos en las zonas costeras y céntricas que aumentaban durante la temporada de verano: el congestionamiento del tránsito, la falta de estacionamiento y el deterioro de las calles en la zona céntrica. Mientras que en los barrios se advertía la ausencia o escasez de los servicios urbanos (cloacas, alumbrado público, gas, agua corriente) y problemáticas habitacionales por el continuo crecimiento de la población. Asimismo, estas falencias en la infraestructura constituían un impedimento para la instalación o el desempeño adecuado de determinadas industrias en ciertos sectores de la ciudad.

\section{Las visiones sobre turismo y desarrollo}

En las elecciones de 1983 los candidatos a intendente se explayan notoriamente en sus exposiciones y argumentaciones respecto de su visión sobre el turismo y el desarrollo económico de la ciudad de Mar del Plata al momento de presentar sus propuestas políticas. Aquí nuevamente se plantean las preguntas ¿Qué lugar ocupaba 
el turismo en el desarrollo económico de la ciudad desde sus perspectivas? y ¿Cómo se piensa el turismo?

La problemática del desarrollo en la localidad va a ser una de las preocupaciones centrales de varios candidatos. Desde una perspectiva económica se piensa y discute en qué tipo de ciudad se quería: turística o industrial y sobre esa base plantean sus propuestas al respecto. Para Manuel Álvarez, candidato del Partido Intransigente (PI), la actividad turística se complementa con la incipiente actividad industrial, pero esta última es la que requiere generar acciones públicas para su fomento a fin de incrementar el desarrollo de las industrias ya existentes (pesquera, construcción, textil, alimenticia, metalúrgica) y alentar la instalación de industrias complementarias y derivadas de las ya existentes. Este candidato, con una visión especial de la realidad local, propone la implementación de una planificación para lograr un desarrollo al que llama «armónico» que permitiese a la ciudad delimitar las áreas que deberá ocupar cada sector económico y ordenar el crecimiento urbanístico. Respecto del turismo, Álvarez entiende que el atractivo actual de la ciudad no se basa exclusivamente en las playas «sino que la ciudad en su conjunto, por su dinámica, su variedad de espectáculos, sus posibilidades de esparcimiento, constituye de por sí un elemento de singular magnetismo para el turista». ${ }^{21}$ Para ello propone que Mar del Plata sea el centro de la región Mar y Sierras a partir de la creación de pequeños centros suburbanos turísticos alrededor de la ciudad revalorizando los recursos naturales que posee. Con una mirada particular de la actividad turística, este candidato valora y reconoce la potencialidad del entorno periurbano y rural de la ciudad y realiza proposiciones al respecto. El desarrollo de la ciudad es pensado por este candidato desde una perspectiva que integra las cuestiones económicas con las sociales y el turismo es entendido en una concepción más amplia al buscar diversificar la oferta de ocio a partir de nuevas modalidades turísticas por fuera del tradicional producto de sol y playa.

De igual manera, Jorge Lombardo, candidato del Partido de la Juventud Democrática (PJD), entiende que el desarrollo económico de la ciudad debe basarse tanto en el turismo como en la industria. Lombardo sostiene que son «dos términos que lejos de contraponerse deben conciliarse en una complementación que eleve su

${ }^{21}$ El Atlántico [Mar del Plata], oct. 1, 1983, p. 2. 
gravitación en la economía local y regional».22 Así, el fortalecimiento de la industria es crucial por lo que se debe fomentar la radicación de nuevas industrias y en particular de aquellas que aún no existen y estén orientadas a satisfacer la demanda local. De esta manera, permitiría elevar las posibilidades de aumentar el empleo además de evitar el innecesario encarecimiento de los productos. En cuanto al turismo, Lombardo es consciente de la limitación que tiene su tradicional producto turístico de carácter estival y busca extender la temporada veraniega a partir del fortalecimiento del hábito de visita de contingentes turísticos durante el invierno. Esta idea de desestacionalizar la actividad turística requiere generar nuevos atractivos acorde a la temporada invernal, diversificando, de esta manera, la oferta turística de la ciudad. Para ello se piensa en una integración con la región que permita incorporar recursos turísticos extralocales. Así, el desarrollo económico de la ciudad está pensado desde estos dos ejes buscando una diversificación productiva y con base en una planificación. Desde su perspectiva, el futuro gobierno debería «conciliar el desarrollo de ambos roles para que nunca entren en colisión, sino que se complementen y contribuyan a generar los ingresos que el bienestar de la población requiere». ${ }^{23}$

También Teodoro Bronzini, candidato del PSD, plantea que ambas actividades económicas deberían ser las bases del desarrollo local haciendo hincapié en la actualidad del turismo y la potencialidad de la industria. A partir de identificar dos ciudades, la permanente, dominante en la temporada de invierno centrada en la actividad industrial y comercial, y la temporaria, predominante en los meses de verano y vinculada al turismo, entiende que resulta necesario planificarla. En este sentido plantea que el desarrollo futuro de la ciudad requiere de una inteligente planificación y luego agrega «un concepto rector para esa planificación necesaria a que nos referimos debe ser la racionalidad técnica y administrativa de esa estructura, preparada para la prestación más eficiente y al menor costo posible».24 Así, la planificación se plantea como una herramienta necesaria para el desarrollo local. Al hacer mención sobre las propuestas en turismo, Bronzini señala que Mar del Plata buscará completar su desarrollo hacia el sur a fin de transformarse en un polo de atracción y centro receptor y radiador de toda la costa litoral bonaerense. De este modo, se plantea un desarrollo

${ }^{22}$ El Atlántico [Mar del Plata], oct. 1, 1983, p. 3.

23 El Atlántico [Mar del Plata], oct. 1, 1983, p. 3.

${ }_{24}^{2}$ El Atlántico [Mar del Plata], oct. 1, 1983, p. 2. 
de la oferta turística por fuera del área central de la ciudad con cierto alcance regional, a fin de otorgarle cierta centralidad territorial pero que continúa vinculado al espacio costero. Su visión del turismo es tradicional, centrándose en el monoproducto de sol y playa, sin otorgar ninguna innovación a las proposiciones políticas. Para este candidato, el desarrollo económico local se basa en el impulso a la actividad industrial y en la continuación de la actividad turística tradicional.

Asimismo, el candidato del PJ, Gustavo Demarchi, en coincidencia con estos candidatos sobre la importancia del turismo y la industria en el desarrollo de la ciudad, remarca en su discurso la necesidad de la planificación del territorio. Las distintas funcionalidades de las áreas que lo conforman (residencial, comercial, administrativa, industrial, turística) requieren de una organización a fin de asegurar un adecuado desarrollo, evitando privilegiar algunas zonas en perjuicio de otras. Aunque las cuestiones sociales y urbanas necesitarían de mayor atención por parte del gobierno local. Así, la planificación es entendida como una tarea que requiere necesariamente la participación de la comunidad en su conjunto con el fin de defender sus propios intereses. Al hacer referencia al turismo, Demarchi señala la continuidad del modelo turístico masivo, aunque expresa la intención de asignarle un sentido social, de acuerdo al pensamiento justicialista. Para ello aprovecharía las inversiones realizadas por los gobiernos anteriores. Así, este candidato, con una visión acotada del turismo, plantea como propuesta la continuidad de un modelo turístico que ya había entrado en crisis en la década anterior con escasas innovaciones.

Por otra parte, había otros candidatos que, si bien plantean la necesidad de basar el desarrollo de la ciudad en el turismo y la industria, tienen una actitud que apela a «mantener» la actividad turística en particular, como así también sosegar el crecimiento de Mar del Plata, dada la inestabilidad social y económica por la que atravesaba la ciudad acompañando la crisis del país. En este sentido, Alfredo Battaglia, candidato del Partido Comunista (PC), entiende que dadas las riquezas naturales que posee en su territorio resulta necesario diversificar la estructura productiva a partir del fortalecimiento del sector primario. Respecto del turismo, y en línea con su ideología partidaria, Battaglia considera que los gobiernos locales han estado «desviando» su atención y los recursos dinerarios del arca municipal, y por lo tanto del pueblo, para el sostenimiento y financiación de este sector, lo que connota una visión negativa hacia la actividad turística. Es por ello que este candidato propone mantener la estructura 
turística, sin realizar erogaciones para su ampliación. Si bien Battaglia manifiesta la necesidad de diseñar un plan de emergencia a corto plazo a fin de brindar soluciones a la población, también plantea en un momento posterior generar un plan para el desarrollo «armónico» de la ciudad y de todo el partido. Así, para este candidato ni el turismo ni el desarrollo económico local eran temas prioritarios en su agenda política denotando una visión acotada al respecto.

Otro candidato que manifiesta la necesidad de contener el crecimiento de Mar del Plata dada la crisis socioeconómica por la que atravesaba el país era el candidato de la UCR, Ángel Roig. En una de sus alocuciones plantea «evitaremos el crecimiento explosivo como medio de defensa de la escala humana de la ciudad, limitándola en nuestra gestión a poco más de lo que es hoy».25 Este candidato, si bien señala la importancia y la complementariedad del turismo y la industria en la economía local, se enfoca en la problemática urbanística y social de la ciudad. Para poder controlar un desarrollo, al que denomina armónico, entiende que se debe recurrir a una planificación que establezca normas para este proceso. En cuanto al turismo propone una serie de acciones que apuntan a mejorar la gestión del turismo y desestacionalizar la actividad a partir de la creación de un fondo de promoción turística y de un sistema de información turística y la generación de un calendario anual de eventos. Estas acciones demuestran una visión particular del turismo que denota la incipiente apertura para adecuarse a la dinámica de la realidad turística local.

Entre todos los candidatos es Juan Carlos Mantero, candidato del Partido Demócrata Cristiano (PDC), quien va a plantear desde una visión más amplia un desarrollo integral para la ciudad. Mantero entiende que se debe promover la integración de todos los sectores de la economía a fin de, concertadamente, generar y expandir la actividad industrial a la vez que modificar el rol turístico y de esta manera hacer de Mar del Plata el centro proveedor de servicios a nivel regional. Su idea es generar una estructura económica más dinámica y menos cíclica «superando el proyecto exclusivamente turístico y las insuficientes inquietudes de industrializar. Es necesario plantearse el Desarrollo Integral». ${ }^{26}$ Un desarrollo que integre sus distintas ramas económicas, que induzca a la participación ciudadana y promueva la solidaridad

${ }_{25}$ El Atlántico [Mar del Plata], oct. 1, 1983, p. 3.

${ }^{26}$ El Atlántico [Mar del Plata], oct. 1, 1983, p. 3. 
de la comunidad. Su visión del turismo es amplia dada su mirada integral. Entiende que el territorio local debe generar vínculos con el territorio regional, es por ello que propone promover el cambio de rol de Mar del Plata de mero receptor de visitantes a proveedor de servicios turísticos a la región. Entiende que el sector privado debe asumir un rol más activo en el quehacer turístico por lo que propone incentivar su mayor participación en el desarrollo turístico. Considerando la importancia que tiene la difusión del destino y retrotrayendo experiencias municipales respecto a la participación del sector privado en la gestión del turismo, plantea la creación de un Ente Turístico Mixto de Promoción. Por otra parte, en la consideración de la importancia que tiene la vinculación turista-residente propicia la realización de encuentros y espectáculos destinados a su integración.

Respecto de las problemáticas urbanas y sociales es posible observar cómo se posiciona al habitante del barrio frente a los sectores vinculados a la actividad turística en la visión de los candidatos a intendente. Mar del Plata en la década del ochenta continuaba registrando importantes niveles de crecimiento en varios aspectos. Si bien el ingreso de turistas a la ciudad había entrado en un amesetamiento de la curva, la población local continuaba incrementándose año tras año. ${ }^{27}$ Esta situación derivaba en graves problemas de infraestructura en los barrios que, al igual que en la década del setenta, se contraponía a la realidad de las zonas turísticas de la ciudad. Así, las propuestas de los candidatos van a tender a dar respuesta a estas problemáticas urbanas y sociales. Sin embargo, algunos candidatos (PC, PJ, Partido Obrero y Movimiento al Socialismo), desde una visión más acotada del desarrollo en general, entienden que el esfuerzo estará dirigido primordialmente a solucionar estas cuestiones. En tanto otros candidatos con una mirada más abierta piensan en plantear políticas que den respuesta de manera integral a todos los sectores de la población y ramas de la actividad económica (PDC, PJD, PI).

\section{4- Dos momentos, dos visiones}

A principios de la década del setenta el turismo masivo de sol y playa en Mar del Plata comenzaba a mostrar ciertos signos de agotamiento que se advertían a partir de

${ }_{27}$ De acuerdo al Censo Nacional de Población y Viviendas de 1980, Mar del Plata registraba 414.696 habitantes en 1980. Al respecto, Municipalidad de General Pueyrredon, Departamento de estadística, «30. ${ }^{\circ}$ aniversario 1965-1995», Mar del Plata, MGP, 1996. 
un cambio en la composición de la demanda turística, la incipiente degradación del recurso natural playa y el congestionamiento de los espacios urbanos en torno a la costa. Algunos actores socioeconómicos predominantes del escenario local habían comenzado a plantear desde la década anterior que resultaba necesario diversificar la economía local a partir de dar un impulso al sector industrial a fin de asegurar el desarrollo económico de la localidad. La persistencia de estos indicios de agotamiento del turismo masivo impulsaría a los empresarios vinculados al sector industrial a plantear nuevamente estas demandas al elenco político local. Muchos de los candidatos a intendentes en las elecciones de 1973 se hacen eco de estas peticiones y en función de ello plantean sus propuestas.

De esta manera, el desarrollo económico de la ciudad es pensado en función de la crisis que se estaba viviendo. Para superarla, los candidatos van a coincidir en su mayoría que se requiere estimular la industria, fortaleciendo y diversificando las existentes (la pesca, la textil, la alimentaria) y promocionando las nuevas, además de promover la creación del Parque Industrial. Esto permitiría generar puestos laborales de carácter permanente y una economía local más estable. De este modo, el desarrollo económico de la ciudad es pensado desde el impulso que se le debe dar al sector industrial, cumpliendo con los intereses de aquellos actores socioeconómicos predominantes vinculados a la industria. Sin embargo, solo algunos de ellos hacen hincapié en la importancia de la formulación de políticas agrarias para impulsar la actividad agrícola y ganadera del Partido. La actualización del Plan Regulador era otra preocupación de algunos candidatos a fin de orientar adecuadamente el crecimiento urbano y rural y ordenar las actividades económicas. Además, ciertos candidatos manifiestan la necesidad de concretar importantes obras públicas destinadas a mejorar la infraestructura en general, y en particular para la industria; para ello gestionarían ante el gobierno nacional y provincial su financiación. La inversión en infraestructura serviría asimismo para cubrir las demandas de servicios urbanos en los barrios, cuyo crecimiento poblacional y necesidades generaban también una mayor atención del elenco política local atento a las reiteradas peticiones de los actores sociales de la comunidad residente.

Ahora bien, la crisis que se percibe en la economía local y las problemáticas urbanas y sociales de la comunidad, parecen restar importancia a la crisis que la propia actividad turística estaba comenzando a atravesar. En este sentido, los candidatos van 
a presentar propuestas que tienden a preservar el producto turístico vigente, en ese momento, basado en el turismo de sol y playa. Las problemáticas de la actividad turística expresadas por los actores socioeconómicos del sector giraban principalmente en torno a la gestión del monoproducto sol y playa. De esta manera, las proposiciones elaboradas se centran en la concesión de los balnearios y en la administración de los recursos provenientes de su explotación, debido al reciente traslado del dominio de las playas de la provincia a la comuna. Además, algunos candidatos proponen generar nuevos equipamientos en las playas al sur y norte del centro de la ciudad. Así, se advierte que la mayoría de los candidatos presentan una visión acotada del turismo al circunscribir su desarrollo a la actividad balnearia y no percibiendo las dificultades que paulatinamente estaban emergiendo.

La crisis del turismo masivo en la ciudad, que se había iniciado a mediados de la década del setenta, se agudizaba a principios de los años ochenta como consecuencia de factores económicos, sociales y medioambientales. Esto había llevado a que varios actores socioeconómicos predominantes locales vinculados a la industria siguieran planteando la necesidad de continuar con el fomento de la industrialización de la actividad económica del Partido para facilitar el desarrollo económico local. Las políticas implementadas por los gobiernos militares de la última dictadura (1976-1983) habían sido las responsables del estancamiento económico y su crisis progresiva. Haciendo eco de estas peticiones, muchos candidatos a intendente en las elecciones de 1983 van a continuar con la idea de la necesaria diversificación productiva de la ciudad, con especial atención en el desarrollo de la industria, que se plasmará en sus propuestas políticas.

Bajo esta óptica, los candidatos piensan el desarrollo económico local a partir de la situación crítica de ese momento. Al igual que en 1973, en estas elecciones manifiestan la necesidad de fortalecer las industrias actuales y fomentar las nuevas, mientras se continua con la actividad turística. En efecto, un número importante de candidatos expresan que la actividad turística se complementa con la incipiente actividad industrial, y que, si bien hasta ese momento el turismo había sido la actividad protagónica en el devenir económico de la ciudad, se plantea la necesidad de fomentar la ampliación y diversificación de la actividad industrial. Esta idea de complementariedad entre el turismo y la industria es la que sostienen varios empresarios nucleados en la UCIP. Dado que además esto permitiría aumentar el nivel 
de empleo en la ciudad y la provisión de productos para la demanda local. Así, Mar del Plata ya no sería exclusivamente la ciudad turística, ahora también se intentaba instalar la imagen de una ciudad industrial. El desarrollo económico local se piensa nuevamente, al igual que en 1973, desde el impulso que se le debe dar a la industria. Por otra parte, se entiende que las inversiones en infraestructura no solo van a estar destinada para las actividades económicas, sino también para cubrir las deficiencias urbanas en los barrios de la ciudad. La población continuaba creciendo y sus necesidades también. Por ello los candidatos entienden que hay dos ciudades; para algunos está la turística y la periférica (los barrios), y para otros está la turística temporaria y la permanente (la industrial y comercial); mostrando así la dualidad de la ciudad.

Ante esta compleja realidad, los candidatos a intendente plantean que el desarrollo de la ciudad requiere una planificación. Así, a diferencia de lo planteado en 1973, en 1983 los candidatos incorporan esta herramienta para pensar en el desarrollo de la localidad desde una nueva concepción. La planificación permitiría delimitar espacialmente las áreas que deben ocupar cada sector económico y ordenar el crecimiento urbanístico derivado del aumento poblacional. De esta manera, se lograría un desarrollo que denominan armónico. A estas concepciones se suma la postura de uno de los candidatos que introduce la noción de «desarrollo integral» para designar aquel que integra las distintas ramas económicas del territorio, que induce a la participación ciudadana y que promueve la solidaridad de la comunidad.

La situación crítica del turismo masivo en la ciudad y las demandas de los actores socioeconómicos vinculados al sector turístico pertenecientes a la sociedad tradicional local, insta a los candidatos a pensar en cómo revertir ese escenario. En contraposición a lo sucedido en las elecciones de 1973, en 1983 la mayoría de los contendientes van a proponer innovaciones en la gestión pública del turismo. Por un lado, piensan generar nuevos productos turísticos alternativos al de sol y playa integrando el interior serrano y rural del partido y la región a fin de desestacionalizar la actividad. Por el otro, plantean la generación de instrumentos normativos, informativos y organizativos que contribuirán a mejorar la gestión del turismo. Si bien hay algunos candidatos que, con una visión tradicional de la actividad, entienden que hay que preservar el turismo tal cual se había desarrollado hasta ese momento y no realizan propuestas; la mayoría tiene una visión más abierta del turismo. Así, a partir 
de la comprensión de la problemática turística plantean propuestas que buscan incipientemente superar el monoproducto de sol y playa y actualizar su gestión a fin de mejorar su desarrollo.

\section{Reflexiones finales}

En el presente artículo se ha expuesto una indagación sobre las visiones de los candidatos a intendente de Mar del Plata respecto del turismo y el desarrollo económico, en las elecciones de 1973 y 1983. Así, en las entrevistas publicadas en los periódicos locales a estos actores políticos se pudieron observar argumentos y descripciones, y se fueron encontrando alteridades y posicionamientos discursivos e ideológicos. De esta manera, las narrativas de los candidatos permitieron analizar sus perspectivas (valores y creencias) a la vez que constatar que varias de ellas habían sido animadas por los diversos actores socioeconómicos predominantes del escenario local.

En los años sesenta la economía local, que hasta ese momento había estado basada primordialmente en el turismo, la construcción y la pesca, comienza a mostrar ciertas debilidades por su carácter estacional y cíclico. En especial el turismo había iniciado un proceso de declive que alcanzaría su fase crítica a mediados de la década del setenta. Frente a ello, algunos actores socioeconómicos, vinculados a la actividad industrial, al comercio y a la construcción, empiezan a señalar las limitaciones de este modelo y plantean alternativas para el desarrollo local a partir de su diversificación productiva a través del fortalecimiento de la industria en sus diversas ramas (alimentación, textil, calzado, madera y muebles, plástico, papel, química, minerales no metálicos y metalmecánica). Este grupo de actores socioeconómicos buscaban un modelo que tuviera como base la complementariedad del turismo y la industria. Ante los contextos electorales de 1973 y 1983, estos agentes económicos buscarán que sus problemáticas e intereses sean incluidos en la agenda política del futuro gobierno a través de las plataformas de los partidos políticos. Y es en los argumentos y descripciones de los candidatos donde se pueden observar hasta qué punto estos quedaron plasmados en las perspectivas de estos.

En las elecciones de 1973 los candidatos van a tener una visión acotada de la actividad turística. Las propuestas políticas en torno al desarrollo económico local, planteadas desde diferentes perspectivas y con disímil profundidad en el abordaje, 
tendían a dar soluciones principalmente al sector interesado en impulsar la industria. Claramente, los actores dominantes vinculados a esta actividad habían logrado incluir estas cuestiones en la agenda política local plasmadas en las plataformas. Así, el desarrollo económico de la ciudad se piensa desde el estímulo que se le debe dar primordialmente a la industria a partir de su diversificación y promoción. En este contexto, el turismo queda en una posición menos favorable. La mayoría de los candidatos van a plantear su continuidad en torno al monoproducto de sol y playa soslayando las problemáticas urbano ambientales, económicas y sociales que estaban surgiendo gradualmente.

En cambio, en las elecciones de 1983, los contendientes electorales van a asumir nuevas posturas frente a la actividad turística y al desarrollo. Si bien se sigue buscando la diversificación productiva local mediante el fomento de la industria en todas sus ramas, se piensa en la necesidad de alcanzar un desarrollo armónico de la ciudad entre la industria y el turismo. Un aspecto que emerge de sus narrativas, es la alusión a la necesidad de planificar la ciudad como condición para el desarrollo. Lo mencionan a nivel general, territorial y sectorial. Ciertos avances en determinados proyectos de la agenda política local, lo permitían. La creación del Parque Industrial ya se había concretado a fines de la década del setenta, por lo que una parte de los actores socioeconómicos predominantes locales se encontraban relativamente conformes. En tanto, otros sectores de la economía, vinculados al turismo y al comercio, buscaron que sus inquietudes y preocupaciones fueran incluidas en las plataformas locales. En este sentido, los candidatos van a tener una visión del turismo más abierta que en las elecciones de 1973. El acercamiento a los actores socioeconómicos de la actividad, junto a la participación de profesionales expertos en la materia posiblemente haya contribuido a ampliar esta visión. estos pudieron advertir las dificultades de su explosivo crecimiento en las décadas anteriores y van a presentar propuestas modestas buscando dar respuestas al sector, aunque no serán suficientes para superar la crisis del turismo masivo.

En suma, el análisis y la comparación de estos dos momentos posibilitaron conocer cómo variaron las visiones de los actores políticos del escenario local en un contexto de contienda electoral. Sin dudas, en estas visiones incidieron las interacciones y los vínculos que mantuvieron con los diversos actores socioeconómicos predominantes del espacio local, los cuales poseían disímiles modelos de ciudad. De 
este modo, las diferencias identificadas en los relatos de los candidatos a intendente han permitido avanzar en la comprensión del devenir turístico de esta ciudad balnearia argentina, durante su crisis del turismo masivo en las décadas del setenta y ochenta.

\section{Obras citadas}

\section{Fuentes}

El Atlántico [Mar del Plata, 1973, 1983]

La Capital [Mar del Plata, 1973, 1983]

Municipalidad de General Pueyrredon, Departamento de estadística, $« 30^{\circ}$ aniversario 1965-1995» (Mar del Plata, 1996).

\section{Bibliografía citada}

Álvarez, Norma, «Campañas electorales y estilos políticos: el Partido Justicialista y la Unión Cívica Radical en un municipio de Misiones, 1999», en: Amaral, Samuel y Stokes, Susan, Democracia local. Clientelismo, capital social e innovación política en la Argentina, Caseros, Eduntref, 2005, , pp. 36-56.

Álvarez, Adriana y Reynoso, Daniel, Política económica en Mar del Plata 1946-1996, Mar del Plata, UCIP, 1999.

Castellucci, Daniela, «Actores políticos y turismo: la visión de los candidatos a intendente sobre el turismo en Mar del Plata en las elecciones de 1983», en XV Jornadas Interescuelas/Departamentos de Historia, Universidad Nacional de la Patagonia San Juan Bosco, Comodoro Rivadavia, 2015. Disponible en: http://nulan.mdp.edu.ar/2422/1/castellucci.2015.pdf.

Castellucci, Daniela, «Turismo y política en clave de historia reciente: elecciones y plataformas electorales de una ciudad turística», ABET, Vol. 4, N. ${ }^{\circ}$ 3, 2014, pp. 35-44. Disponible en: http://nulan.mdp.edu.ar/2160/.

Cicalese, Guilermo, «Apertura democrática, gobierno local y políticas urbanas. Nueva apuesta a la construcción de la Mar del Plata balnearia en la década del 80: el caso del Complejo Balneario La Perla», FACES, Vol. 7, N. ${ }^{\circ}$ 12, 2001, pp. 51-75. Disponible en: http://nulan.mdp.edu.ar/83/.

Cicalese, Guillermo, «La crisis del turismo masivo en la ciudad de Mar del Plata, 19761987», en Bartolucci, Mónica, Mar del Plata. Imágenes urbanas, vida cotidiana y sociedad, Mar del Plata, UNMDP, 2002.

Franco, Marina y Levín, Florencia, Historia reciente. Perspectivas y desafíos para un campo en construcción, Buenos Aires, Paidós, 2007.

Gil, Gastón Julián, «Etnografía, archivos y expertos. Apuntes para un estudio antropológico del pasado reciente», Revista Colombiana de Antropología, Vol. 46, N. ${ }^{\circ} 2, \quad 2010, \quad$ pp. 249-278. Disponible en: https://scholar.google.com/scholar_url?url=https://www.redalyc.org/pdf/10 50/105020003002.pdf\&hl=en\&sa $=$ T\&oi $=$ gsbggp\&ct $=$ res\&cd $=0 \& d=8213598334357904160 \& e i=t J H r X p C W K M r Y s Q K A t Y 30$ DA\&scisig=AAGBfmoy6fCfSO9t4e2IYJT-HFzRey7YbQ. 
Malamud, Andrés, «El bipartidismo argentino: evidencias y razones de una persistencia (1983-2003)», Revista Uruguaya de Ciencia Política, Vol. 14, N. ${ }^{\circ}$ 1, 2004, pp. 137-171. Disponible en: https://scholar.google.com/scholar_url?url=https://www.redalyc.org/pdf/29 73/297324373007.pdf\&hl=en\&sa $=\bar{T} \&$ oi $=$ gsbggp\&ct=res\&cd $=$ o\&d=14306861514688667341\&ei $=$ gpLrXv_TC8rYsQKAtY3o DA\&scisig=AAGBfm2rFValJz5IXtYleh6N5Mi8Jl5YgA.

Pastoriza, Elisa, «Sociabilidad política en Mar del Plata. Manifestaciones, discursos y enfrentamientos en torno a las elecciones del 24 de febrero de 1946», en Zuppa, Graciela, Prácticas de sociabilidad en un escenario argentino. Mar del Plata 1870-1970, Mar del Plata, Universidad Nacional de Mar del Plata, 2004.

La conquista de las vacaciones. Breve historia del turismo en la Argentina, Buenos Aires, Edhasa, 2011.

y Guillermo Cicalese, «Una trayectoria poco común. Los socialistas en Mar del Plata», Todo es Historia, Vol. 439, 2004, pp. 24-33.

Pastoriza, Elisa y Torre, Juan Carlos, Mar del Plata: un sueño de los argentinos, Buenos Aires, Edhasa, 2019.

Persello, Ana Virginia, «Las elecciones en la segunda mitad del siglo XX», en Sabato, Hilda, Ternavasio, Marcela, de Privitellio, Luciano y Persello, Ana Virginia, Historia de las elecciones en la Argentina, Buenos Aires, El Ateneo, 2015.

Romero, Luis Alberto, Breve historia contemporánea de la Argentina, Buenos Aires, Fondo de Cultura Económica, 2015.

Romero, José Luis, Breve historia de la Argentina, Buenos Aires, Fondo de Cultura Económica de Argentina, 2013.

Sidicaro, Ricardo. Los tres peronismos: estado y poder económico, Buenos Aires, Siglo Veintiuno Editores, 2017.

Spinelli, María Estela, "Rasgos de la cultura política argentina. Un análisis del enfrentamiento peronismo-antiperonismo, 1945-1983», en Ferrari, Marcela, Ricci, Lila y Spinelli, María Estela, Memorias de la Argentina contemporánea 1946-2002, Mar del Plata, EUDEM, 2007. 